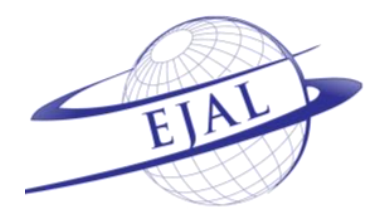

Available online at www.ejal.eu

\title{
Review of Tests, Measurements and Research Methods in Behavioural Sciences
}

\author{
Hamzeh Moradi a * (D) \\ a Nanfang College of Sun Yat-sen University, China
}

Received 19 September 2018 | Received in revised form 23 December 2018 | Accepted 27 February 2019

\begin{abstract}
APA Citation:
Moradi, H. (2019). Tests, Measurements and Research Methods in Behavioural Sciences. Eurasian Journal of Applied Linguistics, 5(1), 175-179. Doi: 10.32601/ejal.543793
\end{abstract}

\begin{abstract}
Tests, Measurements and Research Methods in Behavioural Sciences, Arun Kumar Singh, (2017), Fifth edition. Publisher: Bharati Bhawan Publishers \& Distributors; Binding: Paperback Language: English ISBN-10: 8177097431 ISBN-13: 978-8177097436 No. of pages: ix+616.

(C) 2019 EJAL \& the Authors. Published by Eurasian Journal of Applied Linguistics (EJAL). This is an open-access article distributed under the terms and conditions of the Creative Commons Attribution license (CC BY-NC-ND) (http://creativecommons.org/licenses/by-nc-nd/4.0/).
\end{abstract}

Keywords: measurement; behavioural science; historical research; hypothesis; research methods

The pursuit of systematic and scientific research by experts and researchers in various disciplines has always been a rigorous activity; the most vital part of this systematic process lies in the research methodology which takes up finding answers to the research questions. The present review analyses one of the most comprehensive books on research methodology. The book entitled "Tests, Measurements and Research Methods in Behavioural Sciences" brings together the requisite qualities and adequate information and resources on a conceptually complicated topic of research methodology. Rajasekar et al. (2006) asserted that "research is a logical and systematic search for new and useful information on a particular topic" (p. 2). Research is an integral part of all disciplines and it demands a significant conceptual understanding, a prudent planning and knowledge of various techniques and methods to be applied and implemented in solving research problems. According to Leedy and Armord (2008), "research is a process through which we attempt to achieve systematically and with the support of data to answer a question, the resolution of a problem, or a greater understanding of a phenomenon" (p. 24).

Tests, Measurements and Research Methods in Behavioural Sciences written by Arun Kumar Singh (2017), is a useful and sound resource for undergraduate and

\footnotetext{
* Corresponding author Tel.: +861511212229

E-mail address: hamzeh.m701@yahoo.com
} 
postgraduate students and research scholars in various scientific majors; it provides a substantial broad-based introduction to research methods in various fields including sociology, psychology, and education. This book consists of three major aspects a) construction and standardisation of tests, b) principles of measurements, and c) principals of research methods; it comprises 23 chapters, categorised into three main parts including: principles of test construction (eight chapters); principles of measurements (five chapters); and principles of research methodology (ten chapters). It mostly focuses on developing the skills required to work on research problems, and the problem-solving nature of the research. It also can be a particularly useful guide for the civil services examination and UGC NET/JRF examination; UGC NET stands for University Grant Commission National Eligibility Test, which is a national eligibility test that evaluates and determines the eligibility of Indian national candidates for university / college level lectureship and for the award of Junior Research Fellowship (JRF).

The first part, which starts from chapter 1 to chapter 8 and focuses on the principles of test construction, consists of an introduction to measurement and evaluation, measurement scales, meaning of test, classification, and characteristics of tests. The majority of the discussions in this part are useful for psychology and sociology students; as most of the illustrations and examples in this part are within these majors only.

The second part, which starts from chapter 9 to chapter 13 and focuses on the principles of measurements, covers the general principles of measurements of intelligent, aptitude and achievement. It is a reader friendly section but again in most of the cases, it presents examples of psychology and medical studies that make the understanding more difficult for students and researchers from other majors. With a kind of balancing in presenting examples from various fields of studies, such as fields of social and cultural anthropology, linguistics and language education, behavioural facets of economics and political science and etc., this part can be considerably useful for all students.

The third part, which is the major part of the book and composed of 10 chapters, goes through the research methodology and problem-solving in research process, gives information about sampling methods, social scientific research, single subject experimental research, historical research, problem and hypothesis, reviewing the literature, variables, research design, statistical analysis, and finally writing a research report and as well as a research proposal. In contrast to the first two parts of the book, which present an introduction to various concepts of tests and measurements and provide the definition of key terms and lexical items in a general manner, part three consists of the major discussions involved in research methodology, which is the main concern of the book and essential to the researchers in various fields with distinct educational backgrounds. Part three, as the major part of the book, is highly 
informative and well explained; researchers and students in all majors can enjoy reading and learning from this part; part three can be used as a useful guide within the topics it covers. As mentioned, in contrast to the first two parts which provide only an introduction and general information with regards to tests and measurements, part three specifically focuses of principles of research methodology in an interdisciplinary approach; therefore, the review continues in detail about ten chapters in this part, starting from chapter 14 and ending in chapter 23.

Chapter 14 and 15 cover some of the important topics in research, including probability sampling and non-probability sampling methods, distinguishing features of each strategy, data collection, representation of data, steps for conducting quantitative research and etc. In these two chapters, the author mainly talks about the social scientific research and a broad account of different types of studies. The main purpose of these chapters is to provide the potential researchers with important steps for conducting a scientific research.

Chapter 16 explains about single-subject experiment research. Single-subject research, also sometimes referred to as single-case, is a kind of experimental research in which usually one individual subject participates in investigation and the effect of interventions is vigorously studied on an individual over a period of time (Best \& Kahn, 2006). Referring to Schweigert (2006), the author of the book asserts that "single subject designs focus on individual (or, at most a few) but bring with them the rigors and objectivity of the scientific method, in an effort to determine the effect of an independent variable on some dependent variable" (p. 189). This chapter is useful for medical research and particularly in the area of behaviour modification and drug evaluation.

Chapter 17 focuses on historical research. Historical research is different from research conducted by most behavioural scientists. Referring to Cohen, Manion and Morrison (2002) definition of historical research as "an act of reconstruction undertaken in a spirit of critical enquiry designed to achieve a faithful representation of a previous age" (158); the author further explains that historical research refers to the application of scientific methods to the description and analysis of past events. This chapter gives a general description of historical research.

Chapter 18 provides information about problem and the hypothesis. It gives an explanation on the meaning of problem and subdivides it into two types: a) solvable problem b) unsolvable problem. It also gives explanations on meaning, significance, and characteristics of a good hypothesis. Mangal and Mangal (2013, p. 28) defined hypotheses as "tentative propositions, hunches, or intelligent guesses open to testing as true or false for answering the research questions of the study". Two suggested points about the hypothesis are discussed. First, the author explains that a hypothesis is a testable statement, which means it displays the relationship between those variables 
which are measurable. Second, he asserts that a hypothesis exhibits either a general or specific relationship between variables. On the basis of the degree of generality, research hypothesis can be divided into two types: a) universal hypothesis b) existential hypothesis. In this chapter, some of the given examples are specifically related to psychology research which makes its understanding more difficult for those who do not have enough background in psychology. The sample hypotheses discussed in this chapter are mainly useful for behavioural research; however, it lacks an interdisciplinary approach in explaining the sample hypotheses or rendering the examples.

Chapter 19 gives a detailed explanation on the review of literature with a simple and understandable language; it renders the possible research resources for finding the related literature review and as well as useful procedures for practical search and review. Chapters 20,21 and 22 provide detailed information of statistical analysis that most of the time students and researchers find these complicated statistical analyses formidable to understand completely. Chapter 21 is about research design. It introduces the criteria of research design in three categories; i.e. capacity to answer research questions adequately, control of variables and finally general legibility. Chapter 22 represents the statistical analysis in detail. It introduces some statistical analyses which can be used in psychology and sociology, but also in other fields of research.

Finally, in chapter 23, Singh (2017) demonstrates the effective and precise ways and steps that students and researchers in various scientific fields need to follow in order to write a successful research report or a research proposal. This chapter provides sound and informative information and a detailed description about the structure or the format of a research report. The language of this chapter is easy to understand and to follow up the discussion and in addition the topics discussed in this chapter are very well organised and systematic. Personally, I think, this chapter is one of the best chapters of the book which students and research scholars can learn a lot about the important steps in conducting a research and authoring a good research report.

Tests, Measurements and Research Methods in Behavioural Sciences is a useful reference book and an indispensable resource for students and researchers who engage and deal with research writing. It provides a significant discussion about the research methodology and renders a detailed description of the essentials of principles of measurements and research methods, which finally results in a successful and outstanding research report.

The book with a comprehensible language precisely explains about the important research concepts, principles and methods in detail. It provides a detailed introduction to various approaches and methodologies in social sciences, sociology, educational sciences, statistical studies, and psychological studies. It covers a significant portion of 
theoretical and statistical analysis and has been written in a very precise, efficient, and systematic way. As mentioned, this book proves to be an inestimable and seminal research guide for graduate and postgraduate students and as well as researcher scholars in various research fields in order to conduct and present a scientific and systematic research report or research proposal and to further develop their research competence. It should be mentioned that although this book renders different stages and aspects of research in detail, more examples should be presented from other subject matter fields such as education, economics, linguistics, etc, so that it can widely be used in all other majors and researches.

\section{References}

Best J.W., \& Kahn, J.W. (2002). Research in education. New Delhi, India: Prentice-Hall of India.

Cohen, L., Manion, L., \& Morrison, K. (2002). Research methods in education. London: Routledge.

Leedy, P. D., \& Ormrod, J. (2008). Practical research: Planning and design. New York, NY: Pearson.

Mangal, S. K., \& Mangal, S. (2013). Research methodology in behavioural sciences. New Delhi, Indıa: PHI Learning.

Rajasekar, S., Philominathan, P., \& Chinnathambi, V. (2013). Research methodology. Available at: http://arxiv.org/pdf/physics/0601009.pdf

Schweigert, W. A. (2011). Research methods in psychology: A handbook. Long Grove, IL: Waveland Press.

Singh, A. K. (2017). Tests, measurements and research methods in behavioural sciences. New Delhi, India: Bharati Bhawan Publishers \& Distributors.

\section{Copyrights}

Copyright for this article is retained by the author(s), with first publication rights granted to the Journal.

This is an open-access article distributed under the terms and conditions of the Creative Commons Attribution license (CC BY-NC-ND) (http://creativecommons.org/licenses/by-nc-nd/4.0/). 